\title{
Research on the "Gold Course" Model of English Film and Television Appreciation Course Based on the Production-Oriented Approach
}

\author{
Ying Huang \\ Wuhan Institute of Design and Sciences \\ Wuhan, China
}

\begin{abstract}
The purpose of this paper is to explore the gold course model of English film and television appreciation course, which aims at cultivating students' comprehensive ability of using English, takes production oriented approach as teaching theory and English film as teaching content. The author takes the movie "The Devil Wears Prada" as an example to carry out specific teaching experiments and classroom teaching design.
\end{abstract}

Keywords—gold course; production ability; English film

\section{INTRODUCTION}

At the annual meeting of the International Forum on Higher Education in 2018, the director of the Department of higher education of the Ministry of Education said that colleges and universities should comprehensively sort out the teaching content of each course, eliminate the "water course" and create the "gold course", and the course content needs to be "high-level", "innovative" and "challenging". In order to build a "gold course", College English teaching should focus on the cultivation of practical talents with speculative ability and international vision, and the cultivation of talents with higher comprehensive English application ability, especially the output ability of English speaking, writing and translation. The English film teaching mode based on the production oriented approach can optimize the teaching structure and improve the classroom teaching effect; through the English film, students can learn authentic English expression and improve their oral and writing ability; at the same time, students can also learn English culture from the English film, cultivate their English thinking ability, avoid the use of Chinglish, improve their thinking ability and be able to use English flexibly for oral and written expression

\section{THEORETICAL BASIS}

The purpose of production oriented approach is to improve the effect of college English classroom teaching, improve students' ability of speaking, writing and translating, and cultivate students' humanistic quality. The teaching idea of the production oriented approach includes: taking learning as the center, combining learning with application and whole person education. The output oriented approach advocates that college English classroom should be learning centered, different teaching methods serve different teaching contents, and use flexible classroom forms and teaching tasks to promote the generation of effective learning. At the same time, classroom teaching should not be a simple explanation of text content and knowledge points, but a design of different output tasks based on text content, let students learn and use at the same time, realize the integration of learning and using; Finally, College English classroom should not only achieve the instrumental goal of improving students' English language ability, but also achieve the humanistic goal of cultivating students comprehensive cultural literacy, such as thinking ability and independent learning ability. The selection of materials in College English classroom should not only help students to establish correct outlook on life and values, but also promote cross-cultural communication and cultivate students' ability to spread Chinese culture.

The three key links in the process of output oriented teaching are: driving, promoting and evaluating. Different from the traditional teaching mode, the output oriented approach will show students a communicative task at the beginning of each unit, and let them try to complete it. When students complete this communicative task, they will feel the lack of language level and communicative ability, and then have the desire to learn. In order to improve the efficiency of the classroom and realize the efficient classroom, the completion of the driving link can refer to the flipped classroom teaching mode, which is made by the teacher into a short video, in the form of micro class and completed by the students after class. The promotion link is designed different subtasks by the teacher according to the learning material, and students gradually complete small subtasks to promote the completion of large output tasks. The evaluation link is the teacher's evaluation of students' learning effect in the promotion link. Teachers need to have specific evaluation criteria for different types of output tasks, which is convenient for students to check the effect of their own learning.

\section{The CURRENT SituAtion AND DifFiculties OF COLlege ENGLish Class}

At present, most of the College English courses in our country are faced with the characteristics of many contents, limited class hours and low learning efficiency of students. Classroom teaching is often like watching the flowers on the horse. Teachers are eager to complete the teaching plan and 
cram students with a large number of language knowledge points. However, students' absorption of a large number of language knowledge points is very limited, and it is impossible to achieve the cultivation of students' comprehensive ability of using English in the classroom. Secondly, the content of the course is single and the students are lack of interest. The traditional college English curriculum takes listening and reading as the teaching content, and the analysis of language knowledge points as the teaching focus. Long term single teaching mode and boring teaching content will weaken students' interest in English learning. At the same time, the lack of real communication context leads to the lack of output ability of students' speaking, writing and translation. Although college students have been learning English since childhood, there are few or no opportunities to contact and communicate with native speakers. The lack of real and natural language communication environment for a long time leads to the lack of English thinking of students. In the process of language communication, Chinglish expression appears frequently. At the same time, the lack of cultural background knowledge will also restrict students to correctly interpret the verbal and nonverbal information conveyed by the communication objects. Finally, due to the absence of thinking ability in College English classroom, many students can only learn by rote in the process of learning English, but can't achieve the purpose of using English for oral and written communication.

\section{TEACHING DESIGN OF ENGLISH FILM AND TELEVISION APPRECIATION COURSE}

Based on the concept of output oriented teaching, the author designed teaching link of a unit of English film and television appreciation course, and carried out a 4-week teaching experiment, with 2 class hours per week. The teaching object is the sophomore of clothing design major, and the teaching film is the Devil in Prada. In order to test the teaching effect, after the experiment, the author used her peers to listen to the class and evaluate the class, students completed the questionnaire survey and interview to collect feedback on the classroom teaching effect.

\section{A. Teaching Theme}

The author chooses "fashion" as the theme, takes "fashion" as the communication background, and takes "success and happiness" as the main line of teaching. On the one hand, fashion is in line with the professional background of students majoring in fashion design. On the other hand, the discussion on the theme of success and happiness is of positive significance to help students establish a correct outlook on life and values.

\section{B. Teaching Goals}

The teaching goals are divided into three goals: language, culture and humanity. Among them, the language target includes: 1) the vocabulary goal - the expression of 30 words and phrases (e.g., gird your lions, run your errands, tick out); 2) the hearing goal. The film is divided into four main parts: Andrea, who just started to work in the field of fashion, was totally unable to adapt to the job; Andrea listened to suggestions, began to learn fashion and dressing, and got
Miranda's recognition and approval for her work; Andrea's life appeared inflection point, and her life and feelings were in crisis; Finally Andrea planned to find herself and pursue her dream. Students are required to listen to and enjoy the four clips in the film to complete the output task of retelling the story content; 3 ) oral goal, which requires students to complete the oral discussion activities related to the film theme or the film cultural elements on the basis of watching the film; 4) writing goal, which requires students to complete the writing task of an expository text or argumentative paper on the film related topics. It is required to use the words that have appeared in the film to express, and have certain speculative in content.

Cultural goals mainly include the understanding of western fashion cultural elements, including the history and culture of luxury brands. These luxury brands include Armani, Chanel, Dior, Fendi, Prada, etc. Meanwhile, through the film, students can also learn about famous fashion designers, such as Oscar de la Renta, Yves Saint Laurent, Christian Dior, etc.

The humanistic goals mainly include watching the film, students can realize people's pursuit of truth, goodness and beauty, realize the true meaning of life, and establish a correct outlook on life and values. Students can reflect on whether they can lose their true self in the process of seeking fame and wealth through watching movies, and then understand the definition of success and happiness.

\section{Task Design}

The task is presented in the form of scene performance: according to the film "The Devil Wears Prada", the following two scenes are simulated and adapted in groups. Scenario 1: suppose you graduate from university and are going to apply for a job as a fashion designer in a top international fashion design company, how to make yourself stand out. Team members can play different roles: interviewers - Fashion tycoons, assistants, and two fresh graduates. This task includes three aspects: language, culture and communication. It is difficult and complex. In order to improve the operability of this output task, teachers divide this task into three levels of sub tasks when designing the teaching process to help students complete this output task. Scene 2: if you were Andrea, the heroine, and had achieved fame and success in the fashion Vanity Fair, but found that this is not the life you want, what would you do? Will you give up the pursuit of fame\& wealth and pursuit of true self? The students are required to adapt the plot of the film and make a sequel and adaptation to the life track of the heroine Andrea, including her career, love and life.

\section{Teaching Process}

The classroom teaching process is based on the teaching steps of production oriented approach: 1) driving; 2) promotion; 3) evaluation

1) Driving: Teachers show students the communication scenes they may encounter in their future work and life, stimulate students' interest in participation, and feel the inadequacy of their language level and communication ability by trying to complete the output task, so as to generate 
learning motivation. The film watched in this unit is "The Devil Wears Prada", the teacher will present two output tasks to the students, one is highly related to their major and future work. By completing this output task, the students can enrich their knowledge of western fashion culture, master some basic skills and expressions of English interview. Another output task is related to the value orientation. By completing this output task, students can not only improve their English language knowledge reserve, but also help students to have a deeper understanding of the meaning of success and happiness, and establish a correct outlook on life and values.

2) Promotion: Teachers need to select input materials reasonably according to the task of output, so as to promote the completion of the task, to complete the two output tasks of the unit, teachers need to design related sub tasks to assist the effective completion of output tasks.

Subtask 1: Vocabulary task, for example, about the use of phrases or slang in the movie, can be set as translation task, using a phrase or slang in the movie to complete the output task of Chinese-English translation. These key language expressions include: gird one's Lion (be ready for action), fish out (find out from a pile of things), pick on (tease, be picky), live in something (live for...), own up to something (confess, admit), etc.

Subtask 2: Audio visual task, for example, ask students to listen to a sentence in the film and complete the output task of dictation sentence; or ask students to listen to and enjoy a segment in the film and complete the output task of retelling the story content.

Subtask 3: Oral task, for example, students can be required to complete oral discussion activities related to the theme of the film or the cultural elements of the film on the basis of watching the film. The issues discussed can be: your favorite fashion brand or favorite fashion designer; as a rookie in the workplace, how can you stand out and become famous; which is more important between material success and spiritual self, and what is the true meaning of happiness and success you understand.

By completing the above three subtasks, students have basically mastered the language expression, cultural knowledge and communication strategies necessary to complete the output task. Students can apply the knowledge to line writing and scene performance. In this process, students can creatively apply the acquired language \& culture knowledge and communication strategies to the completion of output tasks, which is helpful to improve students' comprehensive language use ability.

Under the guidance of teachers, the output task should be carried out step by step instead of "sheep herding". On the one hand, teachers need to guide students to watch the key segments in the film, learn the key vocabulary and expressions, and understand the fashion brands and fashion designers in the film. On the other hand, through the activities of classroom explanation and scenario play, they need to let students understand the interview strategy, the way of survival in the workplace and the true meaning of success \& happiness. At the same time, at the end of the exercise, the teacher should immediately assess whether the students have the ability to complete the output task.

3) Evaluation: The evaluation of output can be divided into immediate and delayed. For the evaluation of oral output task, teachers need to know the content of students' presentation in advance and prepare for the evaluation. Teachers' evaluation needs to be targeted and differentiated. For example, some students may use words accurately and have standard pronunciation; other students may be logical in expression and dialectical in their thoughts. In order to make students' output work measurable and practical, teachers need to work out specific evaluation criteria and items. The specific evaluation items include the following aspects: 1) the writing of lines, including the use of vocabulary and the richness of content; 2) communication strategies, including interview strategies, workplace survival strategies; 3) humanistic values, whether they reflect the correct outlook on life and value orientation; 4) performance effects, including voice intonation, body language, familiarity with lines. The way of evaluation is the combination of student evaluation and teacher evaluation. After each group of students completes the scene performance, the students of other groups need to evaluate, say the advantages and disadvantages of the works produced by the members of the group, and put forward suggestions for improvement. The teacher will evaluate according to the students' opinions. After all groups complete the situational performance, teachers need to summarize the completion of the students' output tasks, affirm the outstanding students and their efforts in and out of class, correct some common grammatical and pragmatic errors, and put forward some suggestions for modifying some unreasonable lines and plots. According to the teacher's evaluation results, students can reflect on their lines and designed plots, and rewrite them. On the one hand, evaluation can help teachers understand the teaching effect, on the other hand, it can help students understand their own learning achievements, improve the output of works, and promote effect of learning.

\section{CONCLUSION}

This paper aims to explore the "golden lesson" mode of college English film and television appreciation courses. Through English films, show students the real and natural communication context, and provide a lot of authentic language input. At the same time, create real communication context for students, stimulate students' expression desire, and to achieve the teaching purpose of learning in use and learning in use, improve students' ability to speak, write, and translate. At the same time, through the appreciation of movies, help students better understand the English culture, so as to cultivate students' English thinking and improve students' thinking ability. 


\section{REFERENCES}

[1] Wen Qiufang, Constructing the theoretical system of "production oriented approach" Foreign language teaching and research 2015. (in Chinese)

[2] Zhang Wenjuan, Learn so that it can be used, with use to promote learning - An attempt of classroom teaching in the link of "promoting" by output-oriented method, China foreign language education 2015. (in Chinese)

[3] Liu Xia, With film and TV appreciation as the carrier, cultivate students' English listening and speaking ability, On the cluster of Foreign Languages 2017: 393-398. (in Chinese)

[4] Zhang Wenjuan, Practice of College English classroom Teaching based on "output-oriented method", Foreign language and foreign language teaching 2016: 106-114. (in Chinese) 